TITLE:

\title{
Tin nitride thin films prepared by radio-frequency reactive sputtering
}

$\operatorname{AUTHOR}(\mathrm{S})$ :

MARUYAMA, T; MORISHITA, T

CITATION:

MARUYAMA, T ...[et al]. Tin nitride thin films prepared by radio-

frequency reactive sputtering. JOURNAL OF APPLIED PHYSICS 1995, 77(12): 6641-6645

\section{ISSUE DATE:}

1995-06-15

URL:

http://hdl.handle.net/2433/43536

\section{RIGHT:}

Copyright 1995 American Institute of Physics. This article may be downloaded for personal use only. Any other use requires prior permission of the author and the American Institute of Physics. 


\title{
Tin nitride thin films prepared by radio-frequency reactive sputtering
}

\author{
Toshiro Maruyama and Tomonori Morishita \\ Department of Chemical Engineering, Faculty of Engineering, Kyoto University, Yoshida-Honmachi, \\ Sakyo-ku, Kyoto 606. Japan
}

(Received 4 January 1994; accepted for publication 7 March 1995)

\begin{abstract}
Tin nitride thin films were obtained by the reactive sputtering method. The metallic tin target was sputtered by nitrogen gas with if magnetron sputtering equipment. To prevent the re-evaporation of atomic nitrogen from the substrate, the depositions were made at the low substrate temperature of $60^{\circ} \mathrm{C}$. Polycrystalline films were obtained at an rf power lower than $90 \mathrm{~W}$. The resistivity of polyerystalline film was $3-14 \times 10^{-2} \Omega \mathrm{cm}$, while the resistivity of amorphous film increased monotonically with decreasing sputtering pressure. For amorphous film, the change in resistivity is attributable to the change in carrier concentration. The decrease in carrier concentration is associated with an increase of $-\mathrm{N}=\mathrm{O}$ combination in the film. The optical energy gap of tin nitride was $1.5 \mathrm{cV}$. 01995 American Institute of Physics.
\end{abstract}

\section{INTRODUCTION}

Tin nitride $\left(\mathrm{SnN}_{x}\right)$ is one of the JV-V compounds and has been scarcely studied. Fischer and Iliovichi ${ }^{l}$ gave the first indication of a compound $\mathrm{Sn}_{3} \mathrm{~N}_{4}$, which decomposes at $360{ }^{\circ} \mathrm{C}$. The $\mathrm{SnN}_{x}$ film has been prepared by reactive sputtering methods ${ }^{2-4}$ and reactive ion plating. ${ }^{5}$ Remy and Hantzpergue ${ }^{2}$ obtained dielectric amorphous $\mathrm{SnN}_{x}$ films by cathodic sputtering. Recently, Rima et al. ${ }^{4}$ obtained stable and well crystallized $\mathrm{SnN}_{x}$ films by dc magnetron sputtering.

Our objective is to prepare tin nitride thin films by using reactive if magnetron sputtering of a tin target. The sputtering parameters used were substrate temperature, if power, and total pressure. The electrical and optical characteristics are clarified, and the deposition condition is discussed on the basis of the measured structure and composition of the film.

\section{EXPERIMENT}

In preparing tin nitride films, rf (13.5 $\mathrm{MHz})$ magnetron sputtering equipment (Osaka Vacuum Co. Ltd.,) was used with a $99.99 \%$ pure tin target of $10 \mathrm{~cm}$ in diameter and $1 \mathrm{~mm}$ thick. The rf power was $20-300 \mathrm{~W}$, the sputtering gas was a $99.999 \%$ pure nitrogen, and its flow rate ranged 10-300 scem. The separation distance berween the substrate and the target was $48 \mathrm{~mm}$. The chamber vacuum just before growth was less than $2.0 \times 10^{-6}$ Torr. The substrate temperature ranged from 40 to $324^{\circ} \mathrm{C}$. It was measured using a chromelalumel thermocouple attached to the front of the substrate holder. The total sputtering pressure ranged $0.66-52 \mathrm{mTorr}$. A $76 \times 26 \mathrm{~mm}^{2}$ borosilicate glass plate was used as the substrate.

The infrared absorption spectra were obtained by means of a Fourier transform infrared spectrometer (Perkin-Elmer System 2000). The samples were prepared by depositing films on silicon (100) single-crystal substrates. The binding energy and composition of the film were measured by $x$-ray photuelectron spectroscopy (XPS). The composition of the film was expressed as the atomic ratio of nitrogen to tin. The crystallinity of the film was analyzed by the $\mathrm{x}$-ray diffraction method (Rigaku RINT 1400-TFD) with $\mathrm{Cu} K \alpha$ radiation. The electric resistivity of the film was measured by the van der Pauw method. The carrier concentration and Hall mobility were measured by using the Hall effect. The dynamic hardness of the film was measured with an ultramicrodynamic hardness meter (Shimadzu DUH-200).

\section{RESULTS AND DISCUSSION}

Smooth tin nitride films were formed on the borosilicate glass substrate. They were transparent and colored light brown on the glass substrate. Figure 1 shows the deposition rate as a function of $\mathrm{rf}$ power and total pressure. At each $\mathrm{rf}$ power, the deposition rate decreases dramatically at pressures above about 30 mTorr. A similar dependence on total pressure was observed in depositing InN film. ${ }^{6}$ Visual observations of the deposition at the high total pressure showed that the surface of the target was covered with a transparent nitrided layer after each run.

The composition of the $\mathrm{SnN}_{x}$ film was not measurable at the inside of the film with $\mathrm{x}$-ray photoelectron spectroscopy because nitrogen atoms were sputtered preferentially during Ar ion etching when the surface was etched to measure the composition at the inside of the film. Therefore, the composition was measured at the surface of the film without $\mathrm{Ar}$ ion etching. Figure 2 shows the atomic ratio of nitrogen to tin at the surface of the film as a function of substrate temperature. The films were prepared at the fixed values of if power $(200$ W) and total pressure ( 4 mTorr). The dependence on substrate temperature is similar to that observed in depositing the InN film. ${ }^{6}$ The atomic ratio at the lowest substrate temperature shows the highest value, although the ratio is still lower than the stoichiometric ratio, $N / S n=4 / 3$. The lower atomic ratio at a higher substrate temperature is attributable to the surface adatom reemissions: i.e., the re-evaporation of atomic nitrogen from the substrate at higher substrate temperatures. ${ }^{6}$ The substrate temperature of about $60^{\circ} \mathrm{C}$ was selected as the lowest temperature which was controllable in the experiments over wide ranges of deposition variables under the effect of plasma heating. In the following discussion, the results are based on the films prepared at a substrate temperature of about $60{ }^{\circ} \mathrm{C}$. Figure 3 shows the atomic ratio of $\mathrm{N} / \mathrm{Sn}$ at the surface of the film as a function of total pressure. The atomic ratio for each if power shows a smaller 


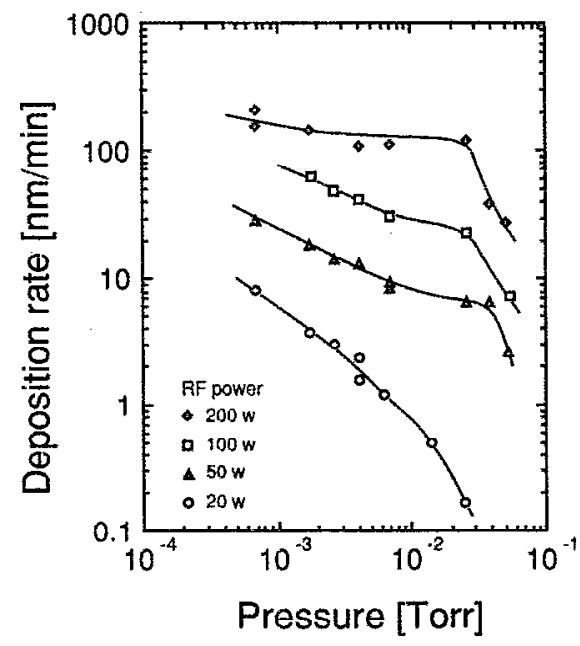

FIG. 1. Deposition rate as a function of if power and total pressure.

value at high pressure, where the deposition rate shows smaller values (see Fig. 1). Thus the decrease in deposition rate accompanies the decrease in nitrogen content. For if power of $200 \mathrm{~W}$, the atomic ratio shows other smaller values at pressures below about $2 \mathrm{mTorr}$. This is attributable to the resputtering of atomic nitrogen from the substrate. ${ }^{6}$ The effect of the resputtering can also be seen in the deposition rate

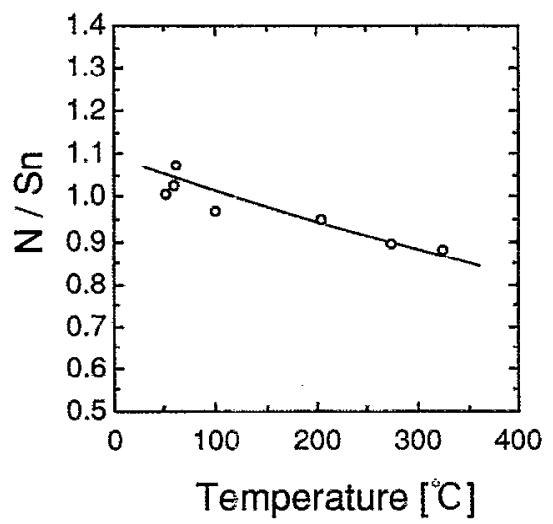

FIG. 2. Atomic ratio of nitrogen to tin at surface of film as a function of substrate temperature at if power $200 \mathrm{~W}$ and total pressure 4 mTorr.

at $200 \mathrm{~W}$ (see Fig. 1); an increase in deposition rate with decreasing pressure is small compared to those for the lower rf powers.

Figures 4(a)-4(d) show the x-ray-diffraction patterns of the film on a borosilicate glass substrate for $200,100,50$, and $20 \mathrm{~W}$ rf powers. They show that the crystallinity depends on $\mathrm{rf}$ power. A polycrystalline film was obtained at an if power lower than $90 \mathrm{~W}$, while an amorphous film was obtained at an of power higher than $100 \mathrm{~W}$. Figures $4(\mathrm{c})$ and

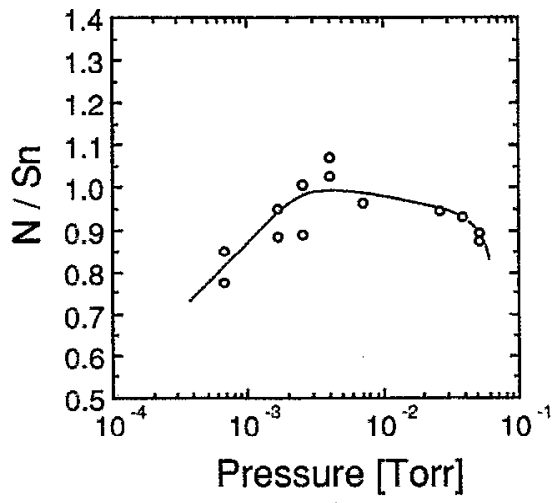

(a)

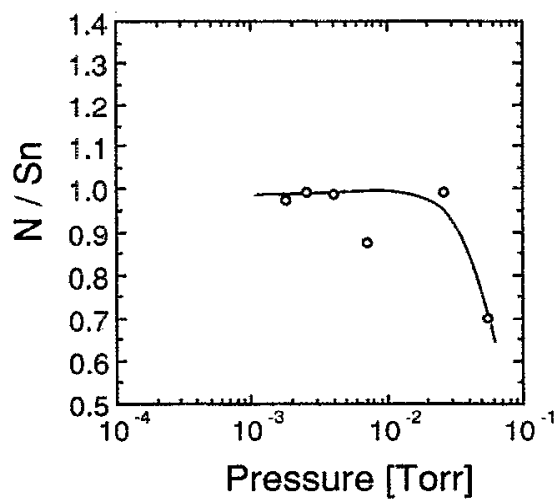

(b)

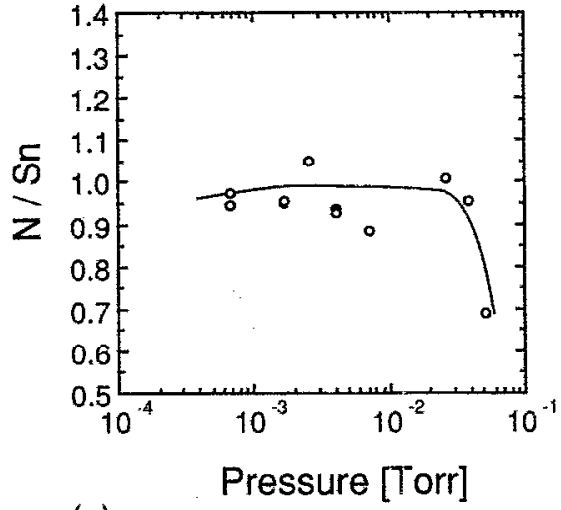

(c)

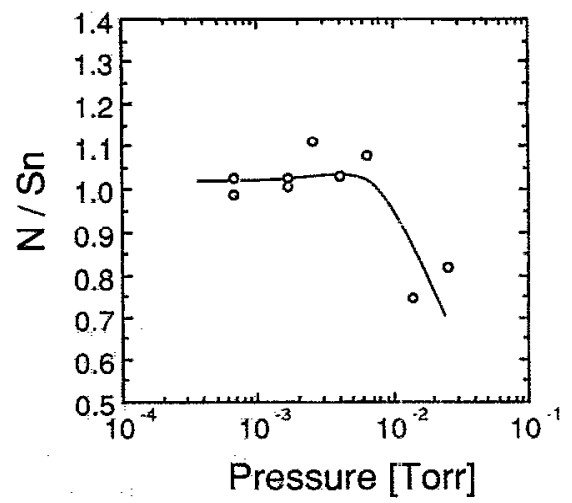

(d)

FIG. 3. Atomic ratio of nitrogen to tin at surface of films prepared at if powers (a) 200 , (b) 100 , (c) 50 , and (d) $20 \mathrm{~W}$ as a function of total pressure. 

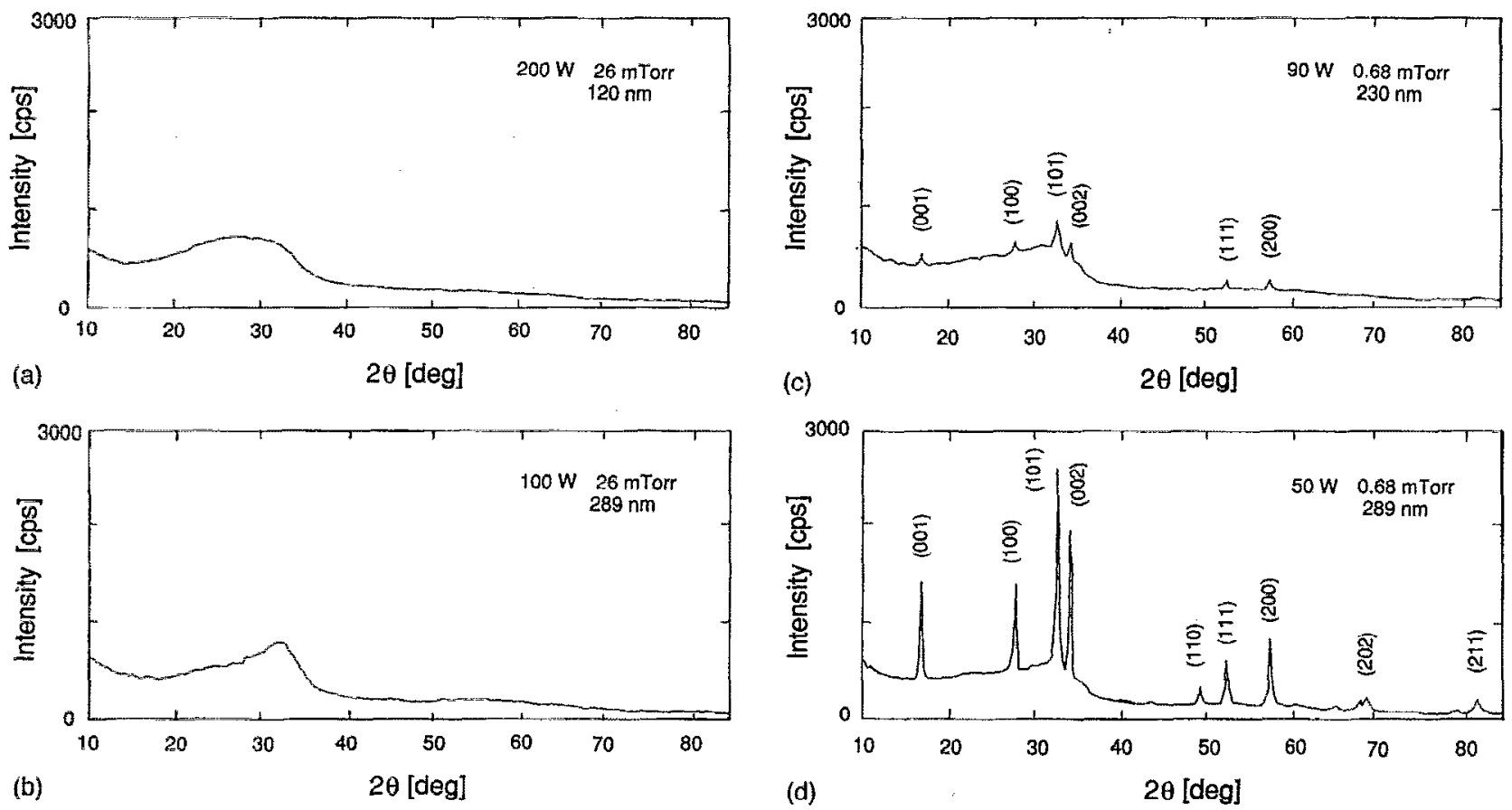

FIG. 4. X-ray-diffraction pattern of films prepared at rf powers (a) 200, (b) 100, (c) 90 , and (d) $50 \mathrm{~W}$ on borosilicate glass. Rf power, total pressure, and film thickness are shown in each figure.

4(d) show that the films are composed of crystallites with hexagonal structure ${ }^{4}$ and with strong (002) plane texturing. It must be noted that the above-mentioned conditions for if power are applicable only for the film obtained at a substrate temperature of about $60^{\circ} \mathrm{C}$. For example, the $\mathrm{x}$-raydiffraction pattern of the film obtained at a substrate temperature of $324^{\circ} \mathrm{C}$ showed that the film obtained at an $\mathrm{rf}$ power of $200 \mathrm{~W}$ was polycrystalline. This is attributable to an enhanced surface diffusion of the adatom at higher substrate temperatures.

Figure 5 shows infrared absorption spectra of the films deposited at three different conditions. Strong bands at 425 and $630 \mathrm{~cm}^{-1}$ in the spectrum for polyerystalline film obtained at $20 \mathrm{~W}$ and $4.0 \mathrm{~m}$ Torr are inferred to characterize the

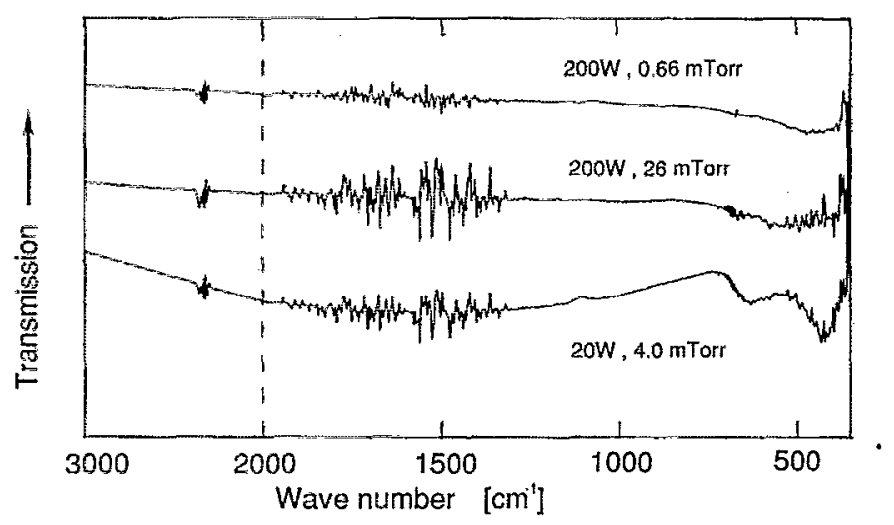

FG. 5. Infrared absorption spectra of films prepared at three different deposition conditions. phonon spectra of tin nitride. The broader peaks for amorphous films obtained at $200 \mathrm{~W}$ are attributable to inclusions of some defects in $\mathrm{Sn}-\mathrm{N}$ bonds.

Table I shows the dynamic hardness of the amorphous and polycrystalline $\mathrm{SnN}_{x}$ films in comparison with that of glass substrate. The polycrystalline film is harder than borosilicate glass. In addition, the films were highly adherent to the substrate. These characteristics are similar to those of $\mathrm{SnO}_{2}$ film which is used for hard coating of glass.

Figure 6 shows the resistivity of the films of high electric conductivity as a function of of power and total pressure. The resistivity of polycrystalline film is $3-14 \times 10^{-2} \Omega \mathrm{cm}$, while the resistivity of amorphous film shows large variations with total pressure.

Figures $7(\mathrm{a})-7(\mathrm{c})$ show the resistivity, Hall mobility, and carrier concentration. The Hall mobility is independent of total pressure, and the value for amorphous film is a little larger than those for polycrystalline films. On the other hand, the carrier concentration for amorphous film depends strongly on total pressure, as shown in Fig. 7(a). Thus, the change in resistivity for amorphous film is attributable to the change in carricr concentration. The carrier for nondoped $\mathrm{SnN}_{x}$ is inferred to be derived from nitrogen vacancies, but a comparison with Fig. 3 shows that any direct relation cannot

TABLE I. Dynamic hardness of $\mathrm{SnN}_{x}$ film and glass.

\begin{tabular}{ccc}
\hline \hline $\begin{array}{c}\text { Amorphous } \\
(200 \mathrm{~W}, 4 \mathrm{mTorr})\end{array}$ & $\begin{array}{c}\text { Polycrystalline } \\
(20 \mathrm{~W}, 0.68 \mathrm{mTorr})\end{array}$ & $\begin{array}{c}\text { Borosilicate } \\
\text { glass }\end{array}$ \\
\hline 566 & 704 & 532 \\
\hline
\end{tabular}




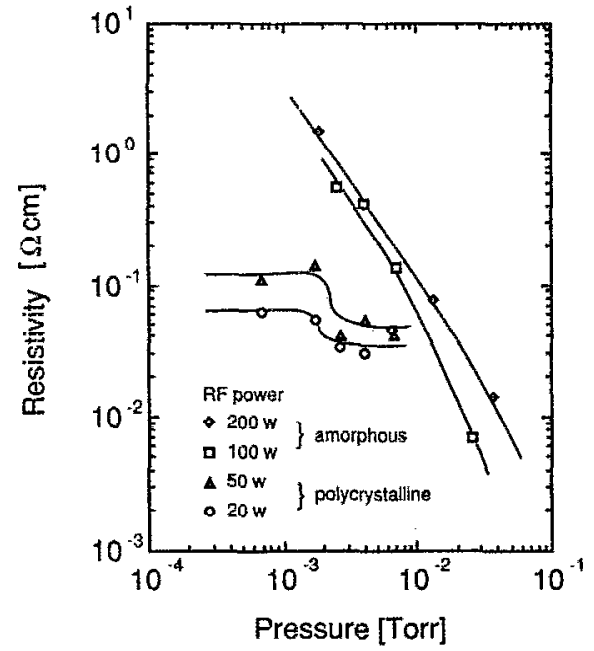

FIG. 6. Electric resistivity as a function of if power and total pressure.

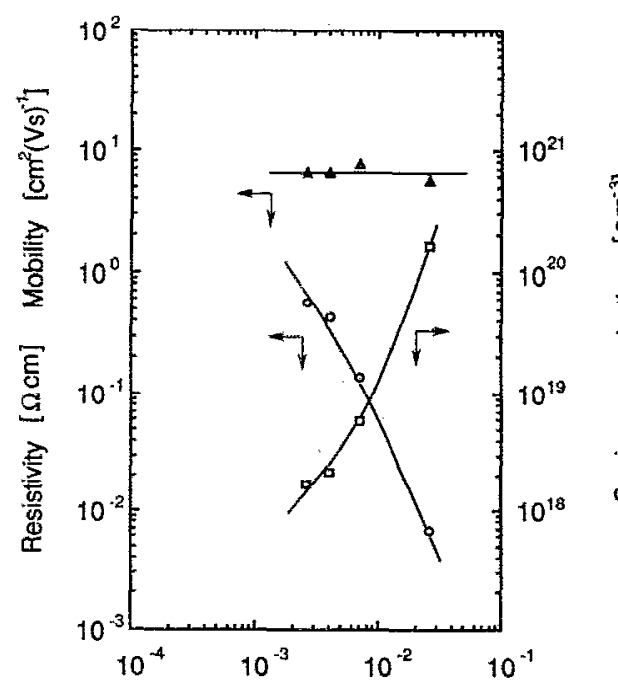

(a)

Pressure [Torr]

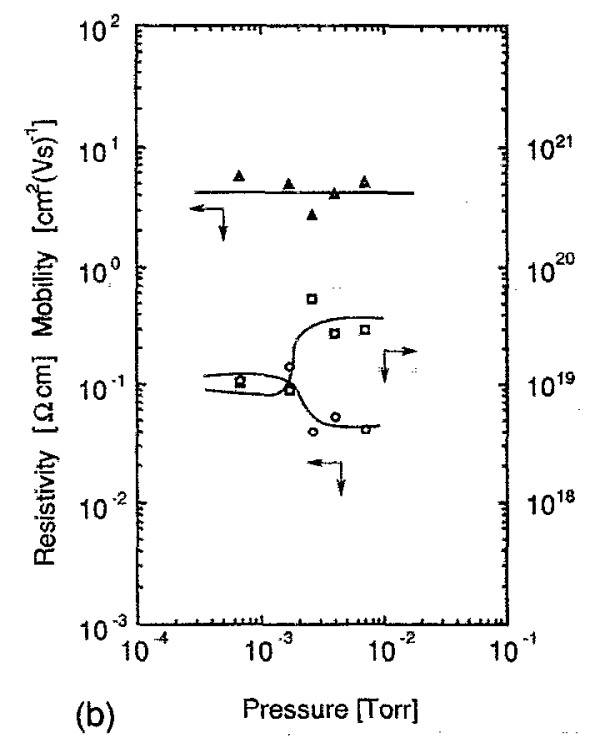

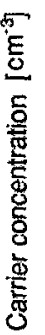

be found between carrier concentration and nitrogen contents of the film.

Figures 8(a) and 8(b) show the XPS spectra of the Sn $3 d$ and $\mathrm{N} 1$ s. Also shown in Fig. 8(a) are the XPS spectra of the $\mathrm{Sn} 3 d$ for the $\mathrm{SnO}$ and $\mathrm{SnO}_{2}$ films. No appreciable difference can be detected between those three peaks. In Fig. 8(b), the spectrum for the film obtained at $200 \mathrm{~W}$ and $1.6 \mathrm{mTorr}$ shows a small peak at $403.6 \mathrm{eV}$, in addition to a large peak of $\mathrm{N} 1 s$ at $397.0 \mathrm{eV}$. The chemical shift suggests that the small peak is attributable to $\mathrm{N} 1 s$ for the $-\mathrm{N}=\mathrm{O}$ combination. The amorphous film of high resistivity always showed the small peak, which became obscured with decreasing resistivity as shown by the spectrum for the film obtained at $200 \mathrm{~W}$ and 26 mTorr. In the meantime, this peak was not observed in the spectrum for polycrystalline film as shown by the spectrum for the film obtained at $20 \mathrm{~W}$ and $4.0 \mathrm{mTorr}$. Thus, the development of the $-\mathrm{N}=\mathrm{O}$ combination in amorphous film is

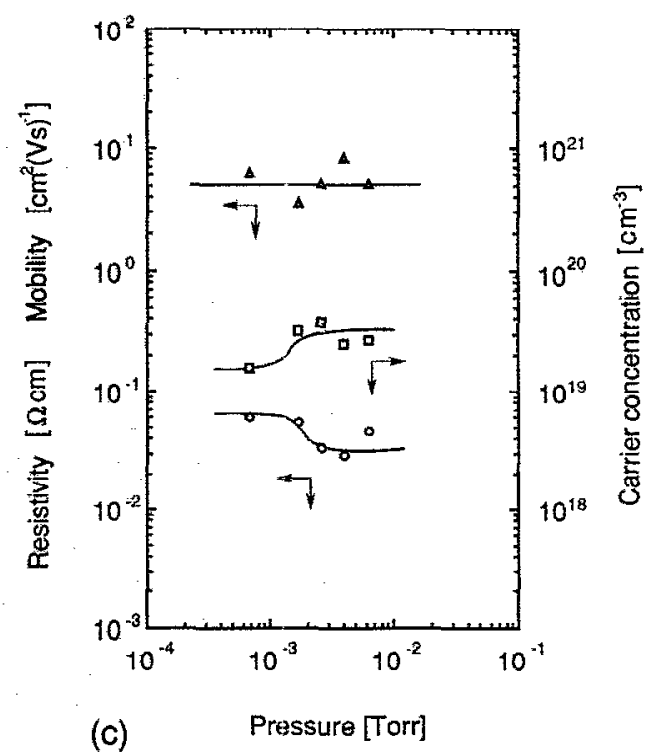

FIG. 7. Electric resistivity, Hall mobility, and carrier concentration of films prepared at if powers (a) 100 , (b) 50 , and (c) $20 \mathrm{~W}$ as a function of total pressure. 

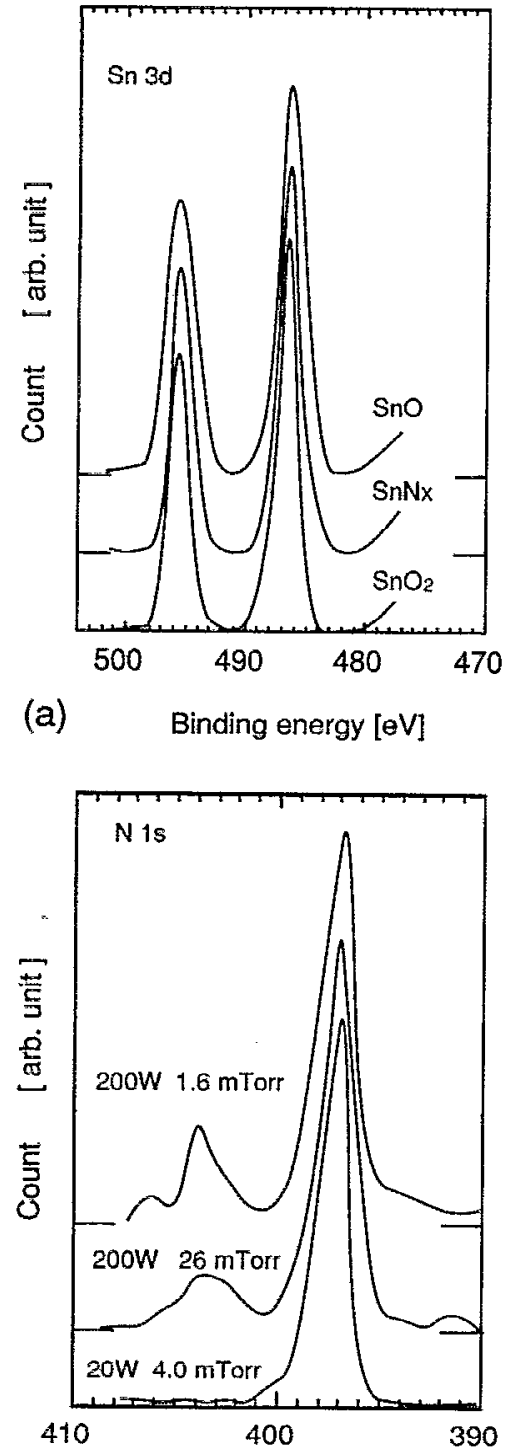

(b)

Binding energy $[\mathrm{eV}]$

FIG. 8. XPS spectra of (a) Sn $3 d$ and (b) N $1 s$.

inferred to be associated with the decrease in carrier concentration. Future studies have to be carried out in order to elucidate the mechanisms: i.e., how the oxygen atoms are incorporated in the film after deposition, and how the combination decreases the carrier concentration.

Figure 9 shows examples of the absorption coefficients as a function of photon energy. The optical energy gap $E_{g}$ for indirect transitions is obtained by extrapolating the full line

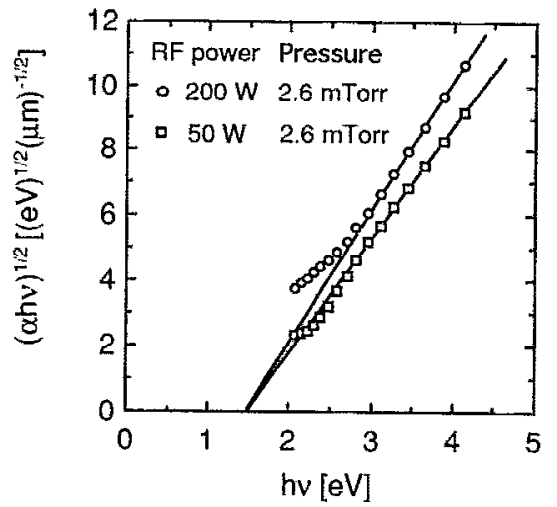

FIG. 9. Relationship between absorption coefficient and energy of incident photons.

to the abscissa. The value of $E_{g}(1.5 \mathrm{eV})$ was independent of deposition conditions, and consequently independent of crystallinity.

\section{CONCLUSIONS}

Tin nitride thin films were obtained by the reactive sputtering method. The metallic tin target was sputtered by nitrogen gas with if magnetron sputtering equipment. To prevent the re-evaporation of atomic nitrogen from the substrate, the depositions were made at the low substrate temperature of $60^{\circ} \mathrm{C}$. Polycrystalline films were obtained at an if power lower than $90 \mathrm{~W}$. The resistivity of polycrystalline film was $3-14 \times 10^{-2} \Omega \mathrm{cm}$, while the resistivity of amorphous film increased monotonically with decreasing sputtering pressure. For amorphous film, the change in resistivity is attributable to the change in carrier concentration. The decrease in carrier concentration is associated with an inclusion of $-\mathrm{N}=\mathrm{O}$ combination. The optical energy gap of tin nitride was $1.5 \mathrm{eV}$.

\section{ACNKOWLEDGMENTS}

This work was supported by the Ookura Foundation. The authors thank K. Nakanishi of Nippon Sheet Glass Co., Ltd. for the Hall coefficient measurements.

${ }^{1}$ F. Fisher and G. Iliovichi, Ber. Deut. Chem. Ges. 41, 3802 (1908); 42, 527 (1909).

${ }^{2}$ J. C. Remy and J. J. Hantzpergue, Thin Solid Films 30, 197 (1975).

${ }^{3}$ J. J. Hantzpergue and J. C. Remy, Thin Solid Films 30, 205 (1975).

${ }^{4}$ R. S. Lima, P. H. Dionisio, W. H. Schreiner, and C. Achete, Solid State Commun. 79, 395 (1991).

${ }^{5} \mathrm{O}$. Takai, Proceedings of the 6th International Display Research Conference, 1986, p. 364.

${ }^{6}$ T. Maruyamia and T. Morishita, J. Appl. Phys. 76, 5809 (1994). 